\title{
Do Funcional ao Simbólico. O que pensam os pares do Campo do Design e o que ensi- nam nas salas de aula.
}

From the Functional to the Symbolic. What the pairs of the Design Field think and what do they teach in classrooms.

Alberto Cipiniuk*

*Possui Licenciatura com Habilitação Plena em História da Arte pela Universidade do Estado do Rio de Janeiro (1978), mestrado em Filosofia Estética pela Universidade Federal do Rio de Janeiro (1985) e doutorado em Filosofia e Letras - Université Libre de Bruxelles (1990). Professor Associado e aposentado do Departamento de Teoria e História da Arte do Instituto de Artes da Universidade do Estado do Rio de Janeiro. Atualmente é Pro- fessor Associado da Pontifícia Universidade Católica do Rio de Janeiro. Tem experiência na área de Desenho Industrial, com ênfase em Desenho de Produto e Comunicação Visual, atuando principalmente nos seguintes temas: campo do design, design, historia social da arte, comunicação visual e representação social da imagem. Líder de grupo de pesquisa registrado no Diretório do CNPq.

\section{Resumo}

Este breve artigo em forma de ensaio relata os resultados de uma pesquisa financiada pelo CNPq sobre o porquê da passagem da dimensão funcional para a simbólica entre as instâncias de legitimação do Campo do Design. Empregando as teorias sociais de Marx e Bourdieu, identificamos o que se pode chamar de identidade dos agentes do campo especialmente no âmbito do Departamento de Artes e Design da PUC-Rio, mas que por homologia, pode ser ampliado para a categoria como um todo.

Palavras-chave: Campo do Design, identidade social dos pares, universo simbólico

\section{Abstract}

This brief article in the form of an essay reports the results of a research funded by CNPq on why the transition from the functional to the symbolic dimension between the instances of legitimation of the Field of Design. Using the social theories of Marx and Bourdieu, we identified what can be called the identity of the agents of the field, especially within the scope of the Department of Arts and Design at PUC-Rio, but which, by homology, can be extended to the category as a whole.

Keywords: Design Field, social identity of peers, symbolic universe 
À parecer simplório ao leitor, mas ele envolvia alguns problemas complexos ou multifacetados, tal como todas pesquisas envolvem, nos quais muita vez este pesquisador se viu em posição de não conseguir respondê-las. A passagem de uma dimensão funcional ou utilitária de um objeto industrial para outra mais simbólica ou abstrata, por exemplo, determinava que soubéssemos primeiramente a definição do que era isso que é um objeto industrial e também quem o projetava, sem esquecer quem o fabricava, posto que quem fabrica não é quem o coloca em circulação. Assim, definir a passagem de uma designação para outra - do funcional para o simbólico - não se resumiu em separar um estilo, uma configuração mais utilitária, para outra mais alegórica ou decorativa. Essa pesquisa não tratava de examinar o que era um "estilo" funcional, tal como os designers normalmente associam a forma "moderna" ou "concretista" aos determinismos utilitários do objeto (a forma seguiria a função), muito de acordo com os ensinamentos da Bauhaus ou Ulm, para um estilo que obsequiasse mais largueza a um expressivismo simbólico romântico, sonhador ou mais "decorativo". Nosso problema não nunca foi um problema de natureza estética, mas também não deixava de sê-lo. Nossa questão passava pela definição do que seria design em um objeto industrial, do que é isso que é um objeto de design e finalmente de quem é o designer. De onde ele surgiu como categoria profissional, como ele pensava e como são as coisas que ele sonha, afinal a metodologia projetual é uma espécie de sonho acordado, no qual o designer antecipa intelectualmente aquilo que vai realizar concretamente.

Se houvesse alguma possibilidade de produzir a biografia de um objeto industrial, se pudéssemos definir a sua ontologia, nossa pesquisa teria como objetivo principal revelar de modo claro e distinto como seria este processo de formação identitária do objeto industrial contemporâneo, como ele se instituiria. E definido o primeiro problema o resto da pesquisa seguiria naturalmente o seu caminho e poderíamos explicar as outras coisas, dominando assim a complexidade daquilo que nos propúnhamos realizar.

Ora, sempre nos pareceu evidente que a definição do objeto industrial era dinâmica e que ela se modificava continuamente. Acontecia do mesmo modo que ocorria quando os pesquisadores se deparavam com os objetos da cultura material ou objetos 
1. Intencionalidade artística, uma potência ou força interna do próprio objeto que não era controlada nem pelo seu criador, nem pelo "zetgeist" (espírito de uma época) no qual ele fosse construído. $O$ objeto se modi-ficaria por si mesmo, movido por uma lógica interna, tal como nos modificamos desde o nosso nasci-mento até a nossa morte.

2. Distinguimos o uso do termo "obra" para os objetos de arte e "objeto" para os objetos industriais. religiosos que passaram a ser vistos ou considerados como objetos de arte, objetos que eram produzidos por agentes sociais de uma área muito próxima ao design. Sabíamos que o significado ou o sentido de um objeto industrial se modificava continuamente, mas não sabíamos exatamente porque este câmbio ocorria. Se essa modificação era determinada internamente, tal como o idealismo alemão defendia uma "kunstwollen"1 para a obra ${ }^{2}$ de arte, ou se fosse um dado objetivo do objeto, tal como é o seu estilo ou então como definimos por conta de uma eventual essência. Se respondêssemos em primeira instância essas questões seria fácil conduzir a pesquisa, daí porque perguntávamos se poderíamos explicá-lo observando-o do lado de fora. Também não tínhamos condições de definir se essa modificação que verificávamos empiricamente era real ou imaginada. Poderia ser de ordem subjetiva, mas também poderia ter sido produzida intencionalmente por alguém ou por algum grupo social e em seguida inculcada em nossas mentes pelos pares do campo. Ademais se essa modificação do objeto industrial fosse eventual ou arbitrária, se ela fosse apenas de sentido ou percepção que o objeto industrial estaria sofrendo, estaria claro que a modificação não acontecia no artefato em si, mas seria por conta das grandes transformações sociais que vivemos, isto é, seriaexterna ou determinada pelas estruturas sociais nas quais o artefato se encontrava e que nosso entrono social nos fazia ver da forma confusa como eles sempre nos levam a ver. Tendo isso mais ou menos certo, foi este o caminho escolhido. Julgávamos que poderíamos entender de forma mais clara o que o objeto industrial seria examinando-o de um ponto de vista externo. Por essa razão optamos pela realização de entrevistas e cotejar as respostas com uma fundamentação teórica calcada na verificação experimental, pois se fosse sujeita apenas à lógica, isto é, a própria estrutura teórica do que estamos discutindo, nossa pesquisa seria transformada em sistema, algo mais próximo à teoria dos sistemas tão cortejada por vários colegas nossos (LESSA, 2009).

Desde o princípio de nossa pesquisa tínhamos claro que não era possível definir isso que é um objeto industrial como uma totalidade acabada, mas julgávamos que era possível identificar como os diferentes grupos sociais, os variados estratos sociais de nossa sociedade de classes percebiam as coisas artificiais que haviam criado, incluindo aí os sentidos e significados dos objetos industriais, e que os cercavam. Assim, ainda era possível definir não os objetos industriais, mas quais valores os grupos sociais empregavam para perceber o que percebiam e com isso produzir algum sentido sobre o seu entorno social.

Há três anos, na ocasião da formulação de nossa proposta de pesquisa, defendíamos que o sentido simbólico do objeto industrial estava sofrendo uma 
mudança radical e estaríamos nos debruçando sobre este tema para entender o seu porquê. Sustentávamos que a sua eventual característica fundamental, antes considerada como sendo um atributo básico deste objeto da cultura material, a funcionalidade, havia cambiado e agora o objeto industrial era visto maiormente como algo simbólico ou abstrato. Por identidade do objeto industrial entendíamos e defendíamos que era possível definirmos algo que possuísse um conjunto de características objetivas que fosse capaz de distingui-lo ou explicá-lo, enfim, que era possível individualizar o objeto industrial em sua natureza integral.

A metodologia empregada para a análise que realizamos foi baseada nas teorias sociais de Pierre Bourdieu (2017). Nas noções de campo, habitus e de como os agentes sociais operam no Campo do Design. Daí, embora Bourdieu nunca tenha mencionado a existência de um Campo do Design, nos propusemos a defender a sua existência para empregá-lo como ferramenta teórica. Dessa forma poderíamos afirmar que os seus agentes se localizavam entre a produção (quem projeta os objetos industriais), a recepção (quem os adquire) e a circulação (quem os legitima ou consagra como aquilo que são). Dentro do campo e diferentemente daquilo que as ciências sociais por muito tempo definiam, não havia atores vivendo ou interpretando papéis específicos no teatro da vida, havia e ainda existem agentes sociais que são sujeito e objeto de suas ações. Pretendentes e dominantes são cate- -gorias muito diferentes de classes sociais definidas unicamente pela sua situação econômica, de proprietários dos meios de produção e aqueles que são explorados como mão de obra despossuída. $\mathrm{Na}$ complexa dinâmica social em que vivemos, os pretendentes ambicionam ocupar o lugar dos dominantes do ponto de vista simbólico e estes lutam pela manutenção do status social que já haviam alcançado. Nessa estranha dinâmica, porém, não existem fronteiras claras e os agentes não lutam empregando argumentos teóricos necessários à fundamentação e ao exercício das suas práticas profissionais, mas pessoalmente entre si por melhores localizações (prestígio e distinção) dentro do próprio campo e contra os campos concorrentes. Seria interessante lembrar que a sociologia de Bourdieu não se opõe à sociologia fundada no materialismo histórico, mas a completa em uma área que Marx não trabaIhou. É claro que as classes sociais lutam pela posse do capital, assim como politicamente os burgueses lutam pela manutenção de seu status quo e o proletariado pela supressão de todas as classes, mas essa luta não é unicamente econômica e política, mas é também simbólica pelo controle das ideias-força, dos princípios e valores nos quais as pessoas vêm buscar uma justificativa para sua razão de ser. Bourdieu amplia a noção de capital econômico (base material do modo de produção capitalista) que Marx empregava e lhe oferece outros desdobramentos, tal como capital cultural, social ou simbólico. 
Empregar a sociologia de um weberiano de origem tal como Bourdieu e os fundamentos críticos sobre o capitalismo encontrados em Marx, não é uma proposição esdrúxula e insensata, pois vários cientistas sociais a estão realizando (BURAWOY, 2010). Aqui no Brasil Jessé de Souza (2018) tem produzido bastante sobre essa associação e discutido com coerência crítica fundamentalismos de ambas as partes. Mas no Campo do Design, não se verificou ainda escritos dessa natureza, tal como propomos agora.

E para avançarmos um pouco mais, de acordo com Bourdieu, as lutas sociais não são unicamente coletivas e apenas determinadas por diferenciais de renda entre a classe dos burgueses e a dos proletários, tal como muitos que não leram Marx acreditam e insistem afirmar. Marx apenas não se aprofundou nos fenômenos sociais que resultavam da assimétrica relação entre capital e trabalho. Do mesmo modo, as lutas sociais não são totalmente individuais como as forças morais estudadas por Weber. Muito dos fundamentos míticos (CIPINIUK, 2017) do Campo do Design, por exemplo, tal como a oposição maniqueísta entre o bem e o mal é produto de crenças baseadas em pensamentos religiosos. Essas afirmações míticas são o resultado da ideia-força de que existe o bem e o mal. Aceitá-las é tão ingênuo como aceitar que a nossa renda e capacidade de consumo é o único responsável pelo dinheiro que se tem no bolso. É evidente que se não temos dinheiro, não podemos comprar, mas muito do nosso consumo não é porque o possuímos, mas porque criamos ideias e valores de que ao consumirmos somos mais dignos e prestigiados do que se não o fizermos.

Dessa dinâmica de embates por prestígio e distinção individuais, associados de modo complementar e não antagônicos ao modo de produção econômi$\mathrm{co}$, constroem-se valores e crenças e pelos quais os agentes se baseiam em suas lutas por lugares sociais. Caso Bourdieu tivesse escrito sobre este tema, ele nos explicaria que as discussões entre os pares do Campo do Design não se baseariam, portanto, em argumentos ou princípios científicos para alicerçar o Campo do Design em busca de um estatuto epistemológico para que pudéssemos competir cientificamente internamente entre nós mesmos ou externamente com outros campos dentro do universo acadêmico, mas que estaríamos empregando julgamentos pessoais, pontos de vista subjetivos, opiniões, hipóteses individuais não comprovadas, crenças personalistas adotadas como verdade sem qualquer reflexão por uma espécie de senso comum entre os pares e sobretudo sem discussão dos seus pressupostos, isto é, os meios pelos quais eles foram obtidos. Mais ou menos homólogo ao que Louis Althusser escreveu sobre o tema da ideologia e dos aparelhos ideológicos (ALTHUSSER, 1980, p. 9.).

Assim, definir a ontologia de um objeto industrial passa necessariamente pela forma como os pares 
do campo definiam ou entendem isso que é o seu objeto de trabalho, a prática do design. Designers desenham ou projetam artefatos ou objetos industriais. Hoje, por conta de uma economia em acelerado processo de desindustrialização (DOWBOR, 2017) e de uma grande ênfase em um capitalismo rentista, os designers se dedicam mais à venda de serviços, contudo a sua prática profissional, a sua formação ainda é orientada para a produção de objetos industriais e a metodologia do seu trabalho, seja ele no projeto ou na forma de aplicação ou uso (serviços) deste objeto, passa pelo projeto, visto pelos pares como uma espécie de quintessência do objeto industrial. Defendemos, portanto, que não há uma singularidade ou essência para o objeto industrial por conta de haver uma dimensão material ou imaterial em relação ao que os designers produzem. Design gráfico, ou design de produto são a mesma coisa, isto é, mesmo que o designer se dedique a projetar para a indústria que fabrica suportes eletrônicos (produtos materiais), seja que se limite a projetar elementos gráficos ou "histórias" para games (produtos imateriais), essas duas formas de trabalho, produtos ou serviços, são o objeto de trabalho dos designers e ele está subsumido ideologicamente ao modo de produção capitalista da sociedade industrial. Designers produzem mercadorias, produtos que devem necessariamente produzir mais valia. Deste modo verificamos que não se encontra uma particularidade própria ou essência para definir a natureza dessa coisa que os antropólogos (MILLER, 2013; MUNARI, 2002; AP
PADURAI, 2015.) classificam como objeto da cultura material e que por algum motivo pode se ressignificar, ou alterar de sentido independentemente do modo de produção ao qual ele passa a existir. Defendemos que o que existe socialmente é a mudança de valores sociais que legitimam ou consagram algo ou alguma coisa como sendo o que são. É a sociedade que cria artificialmente seus arbitrários culturais, portanto quando uma coisa é classificada como sendo um objeto de design, essa coisa não possui em sim mesma nenhum atributo próprio exclusivamente seu, mas o que lhe é próprio ou imanente é definido externamente pelas instâncias sociais que se dedicam a este tipo de trabalho. Mas o sujeito que a define não é uma entidade individualizada como desejava a noção de sujeito romântica e pronada pelo individualismo do final do século XVIII, mas a de um sujeito social definido no seu embate com as estruturas sociais.

Definida a metodologia de trabalho para a pesquisa, nossa primeira reflexão identificou que são os próprios pares do campo que se ocupam da discussão dessa eventual mudança de sentido do objeto de design e concluímos que eles estavam passando pelo mesmo processo que a prática profissional dos designers está sujeita desde o início da sociedade industrial, isto é, desde o momento de sua institucionalização. Assim, tanto os agentes de legitimação (os pesquisadores e teóricos do Campo do Design) e os agentes de produção do objeto industrial (os designers propriamente ditos), assim como quem 
de maneira homóloga. As eventuais variações de sentido percebidas para o objeto industrial, se verificaram indicações ou pistas falsas, pois durante a pesquisa não se confirmou uma alteração entre valor de uso dos objetos industriais, isto é, da dimensão funcional ou utilitária dos objetos, para o valor de troca simbólica, sentido distintivo ou de prestígio social que o objeto eventualmente poderia oferecer. O valor de uso e o valor de troca simbólica se verificam complementares, embora nos dias de hoje o segundo sentido possa, aparentemente, ter tomado um reconhecimento mais abrangente ou hegemônico por conta da sistemática reprodução pelos pares.

Verificamos de imediato que a alteração de sentido ou significado do objeto industrial emergia de hipóteses teóricas de uma disciplina acadêmica com origem no estudo dos sistemas de significação da cultura com base nos estudos da linguagem. São, portanto, originalmente os semiólogos que afirmam que os objetos industriais, assim como todos objetos da cultura material e imaterial, têm como princípio ontológico a sua ressignificação e responderiam a uma relação lógica entre si e destacada da realidade social onde se encontrava. Possuiriam uma autonomia ou independência das estruturas sociais de base e funcionariam com relativa independência da situação histórica concreta na qual se encontravam. Este fenômeno se daria por conta das variações de narrativa. Trata-se, portanto, de um fenômeno de superestrutura, da crença de que as ideias possuem movimento próprio ou autônomo das estruturas sociais, que eles são engendrados por si mesmos. Que o significado de um objeto da cultura material possui como causa outro significado anterior e que eles se sucedem até terminarem ou se extinguirem, tal como um sistema, de modo entrópico. Essa vertente teórica se confronta com a noção que empregamos, na qual as formas de pensamento têm como origem as práticas sociais concretas, nas formas de trabalho dentro do modo de produção de nossa época, a Idade Moderna, isto é, o modo de produção capitalista.

Tivemos ocasião de confirmar que a dimensão narrativa, os termos que passamos a empregar para nomear ações práticas que resultam na concretização dos objetos industriais, foram tomadas de empréstimo aos semiólogos por um pequeno grupo de pares do Campo do Design que tiveram sua formação influenciada pelas teorias de comunicação, nas quais a estrutura da língua é compreendida como equivalente à estrutura social. Um lugar onde as práticas e as dinâmicas sociais são explicadas como se possuíssem uma sintaxe, tal como ocorre com as línguas. Essa influência não ocorreu apenas com os pesquisadores do Campo do Design, mas influenciou fortemente todas as disciplinas das Ciências Sociais.

Deste modo os pares do Campo do Design, aqueles que se ocupavam da legitimação ou consagração disso que finalizou por ser hegemônico como teoria 
3. Defendemos que os pesquisadores do Campo do Design, além de serem estudiosos dos fenômenos que ocorrem em relação à nossa prática profissional, assim como se ocupam do comportamento e das relações sociais que se originam no exercício dessa prática, são agentes sociais que legitimam e consagram valores políticos e ideológicos, portanto a ciência do design. Caso essa ciência exista, sustentamos que não é neutra, mas defende valores e crenças de uma parcela dos pares, especialmente estes que ocupam os bancos escolares. do campo, anteciparam-se a reproduzir e ampliar essas noções. De maneira que de acordo com nosso ponto de vista os fundamentos teóricos do campo, possuem na realidade, um propósito político de classes sociais, trata-se, portanto de algo intencional e que responde às demandas ideológicas deste grupo de agentes. Não houve ainda, portanto, um debate teórico sobre a primazia da dimensão simbólica ou narrativa sobre o valor de uso dos objetos industriais, mas existe uma sistemática defesa política de uma hipótese teórica, que ainda precisa ser comprovada. Ainda que os objetos industriais possam servir para comunicar algo ou alguma coisa, que eles se comportem como signos, que possuam uma estrutura sintática tal como as línguas e daí necessariamente possuírem uma significação, o que não é necessariamente uma mentira, neste caso, no caso em que estamos estudando, a sua função social primeira não é a comunicação, mas a sua finalidade como auxiliar das diferentes práticas humanas determinadas pelo modo de produção capitalista. Foram, portanto, os pares do Campo do Design que passaram a defender politicamente essa afirmação.

Adrian Forty nos oferece um exemplo emblemático quando nos explica a diferença entre o sabão em barra e o sabão em pó para lavagem de roupa, um produto industrial, ainda no século XIX (FORTY, 2007, p. 107-108.). Antes os sabões para lavar roupas eram em barra e depois passaram a ser fabricados em pó. A razão deste câmbio não se de- veu ao seu valor de uso, afinal tanto um quanto o outro, continuaram a servir para a mesma aplicação, a lavagem da roupa. Porém, ao mesmo tempo, por razões mercadológicas, houve uma "modificação" da narrativa e não propriamente do objeto em análise, mas uma modificação do sentido ou significação, pois o sabão em pó passou a ser apresentado como se fosse um produto "novo" que tinha meios de lavar "mais" ou profundamente, ou mais eficazmente, tal como as empresas que fabricam e vendem sabão em pó dos dias de hoje disputam entre si, apenas no âmbito das narrativas, com o emprego de recursos retóricos, músicas envolventes, célebres atores e atrizes consideradas belas e simpáticas, enfim, com auxílio de imagens impactantes, que este ou aquele sabão lava mais branco do que o outro.

Do mesmo modo, o fenômeno ocorre no Campo do Design. Se considerarmos que os mais significativos agentes sociais para a consagração e legitimação dos valores e crenças que vigoram no campo, são também os responsáveis pelo recrutamento e formação dos jovens designers e demais pesquisadores $^{3}$ do campo, verificamos que eles podem operar a modificação de sentido, como se os objetos industriais fossem entidades autônomas (sem valor de uso) e mais ou menos fora do meio social e suas dinâmicas fundadas ora nas práticas, ora nas ideias ou noções que se originam delas. Assim chegamos à conclusão de que são os professores os agentes sociais que determinam a significação daquilo que é 
4. Campo Cultural, Campo da Moda, Campo do Teatro, por exemplo, são termos técnicos formulados por Pierre Bourdieu (2017, p. 64 - 98) e por essa razão grafados em letra maiúscula. Bourdieu jamais empregou a noção Campo do Design. o objeto industrial e, do mesmo modo, são aqueles que mais influenciam a reprodução e ampliação destes valores. Assim, iniciamos nossa pesquisa pelo exame das fontes teóricas ou bibliográficas ${ }^{4}$ que definiam as instituições de legitimação e consagração do campo, isto é, as escolas de design, que de modo geral, depois das famílias, são as maiores e mais importantes instâncias de legitimação dos valores sociais de um campo. Defendemos a importância de observar este espaço social, pois é justamente aí onde se recrutam os neófitos (pretendentes) e onde se espera que ocorra a capacitação dos alunos, embora ainda não possam ser chamados designers, mas se comportam como tais. Assim, depois de um período de formação de aproximadamente quatro anos, estarão capacitados como "produtores" de objetos industriais singulares, isto é, dotados de uma especificidade que outros objetos industriais não possuem, o design. Do mesmo modo, supõe-se, os pares do campo supõem que este agente da produção tenha uma consciência profissional específica, tal como os seus mestres a possuem.

As nossas entrevistas entre os pares do campo foram realizadas durante as Semanas de Design da PUC-Rio - edições 2015, 2016 e 2017 -, que normalmente ocorrem no segundo semestre de cada ano. Nessas ocasiões foi solicitado aos entrevistados que considerado todo o conjunto da exposição, que elegessem aquilo que poderiam chamar de um "bom projeto" ou "bom objeto" de design, dentre os exemplos expostos e em seguida que justificassem tal escolha explicando também o seu entendimento sobre o termo design em si mesmo. Paralelamente, em um segundo braço da pesquisa, digamos assim, foram coletadas, concomitantemente entre os alunos de mestrado e doutorado da mesma Universidade, suas definições para a questão indagando "o que é isso que é o design"?

As respostas que obtivemos foram basicamente as mesmas, isto é, verificamos que havia uma grande unidade ou similitude nas respostas coletadas e por essa razão tivemos a possibilidade de as classificar em três grupos principais e que, a título de exemplo, as apresentamos, tomando como modelo os próprios termos ou palavras dos entrevistados:

Aluno de graduação - "Design é um termo difícil de explicar e está próximo da tentativa de se fazer um objeto funcional, mas com um valor estético agregado".

Aluno de pós-graduação - "Design é uma atividade projetual interdisciplinar voltada para a solução de problemas. Os problemas de design são abertos, isto é, admitem não só uma solução exata, mas inúmeras e complexas, pois lidam com grupos e com indivíduos inseridos em diferentes culturas e ambientes, que formam sistemas sociais com relações interdependentes. Design é interdisciplinar porque pressupõe o estudo dos sistemas sociais e dos conhecimentos específicos envolvidos nas situações-problema" (grifos nossos). 
5. Industrial Design is a strategic problem-solving process (grifo nosso) that drives innovation, builds business success and leads to a better quality of life through innovative products, systems, services and experiences. Industrial Design bridges the gap between what is and what's possible. It is a transdisciplinary profession that harms creativity to resolve problems and cocreate solutions with the intent of making a product, system, service, experience or a business, better. At its heart, Industrial Design provides a more optimistic way of looking at the future by reframing problems as opportunities. It links innovation, technology, research, business and customers to provide new value and competitive advantage across economic, social and environmental spheres. Industrial Designers place the human in the centre of the process. They acquire a deep understanding of user needs through empathy and apply a pragmatic, user centric problem solving process to design products, systems, services and experiences. They are strategic stakeholders in the innovation process and are uniquely positioned to bridge varied professional disciplines and business interests. They value the economic, social and environmental impact of their work and their contribution towards cocreating a better quality of life". Disponível em: http://wdo.org/about/ definition/industrial-design-definition-history/ Acesso em 14.11.2018
Entre os professores e pesquisadores (doutores) ações-problema” (grifos nossos).“Design é uma disciplina e profissão que projetam interfaces físicas e digitais".

Foram, portanto, 34 entrevistados do Campo do Design e os resultados, tanto das entrevistas na Semana de Design da PUC-Rio quanto das realizadas por escrito com os alunos de mestrado e doutorado, foram consideravelmente semelhantes Como consequência, a nossa primeira reflexão se remeteu a preocupante percepção de que não havia discrepância entre os mais graduados e os menos graduados na mesma instituição. Mesmo o entrevistado estando em um nível avançado de especialização, o entendimento do campo pelos agentes não se alterava. Há, portanto, além de uma unanimidade das noções, uma verticalidade das afirmações. Para que o leitor dessas linhas não considere que os entrevistados responderam qualquer coisa, apenas para atender e se desembaraçar rapidamente do entrevistador, gostaríamos de lembrar que elas foram espontâneas e não houve apenas respostas orais durante as Semanas de Design, mas as mesmas perguntas foram respondidas por escrito pelos alunos de pós-graduação (mestrado e doutorado).

Observamos ainda que a maior dificuldade dos entrevistados ocorreu em relação à definição sobre a sua área de atuação, isto é, que prática era essa e para que serviria tal prática social. Na verdade, os pares do campo definem o design como uma coisa, algo em si mesmo, um artefato feito por um designer, mas nunca uma prática social, produzida por conta de uma demanda social. Mencionam o tempo todo que projetam para solucionar problemas dos usuários, mas não refletem criticamente sobre essa autonomização de sua prática profissional. Os entrevistados manifestaram que sabiam descrever aquilo que faziam, mas não demonstraram saber qual o objetivo daquilo que realizavam. Definiam a sua prática profissional para atender ao projeto, às etapas de execução do projeto, mas nunca as verdadeiras ou reais demandas (sociais) daquilo que foi projetado. Sustentam que se o projeto seguir as etapas da metodologia projetual, o objeto é "bom" e necessariamente atenderá o usuário. Não deixa de ser admirável que embora a maioria dos pares tenham mencionado que a prática do design servia

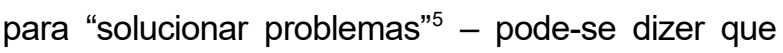
essa afirmação é quase unanime entre os pares -, não fazem alusão aos grupos sociais concretos para os quais eles se destinam. Referem-se idealisticamente "aos homens", "à humanidade" ou aos "usuários", termos absolutamente vagos e difusos para o cientista social. Ora, impressiona e fascina não terem clareza deste ponto. Julgam que o objeto realizado ou projetado por um designer é uma espécie de entidade absoluta, que serve indiferentemente para todos homens e mulheres, em todos os lugares e em todos os tempos. Algo que além de transcender, tempo, espaço e gêneros, não identificam classes sociais, pois tanto ricos como pobres 
"reconhecem" indiferentemente um objeto desenhado por um designer, como sabem identificar um "bom" design apenas olhando o objeto desenhado.

Aliás e muito a propósito, todas as questões dos pares entrevistados parecem se reduzir nos dois extremos dessa complicada e indecifrável equação, ora as questões disso que é o objeto de design se localizam e se resolvem no próprio objeto, ora no seu projetista. Não há nuança ou intermediação do meio social, embora seja também unanime que afirmem que o designer deve se preocupar com o usuário. Os pares do campo classificam um objeto por suas condições objetivas. Se é um "bom" objeto de design, a coisa se explica por conta de quem o projetou "bem", por exemplo, se foi desenhado por fulano que é tido pelos pares como "bom" designer, o resultado certamente será igualmente "bom". Ou então seja por conta de problemas objetivos do objeto, aspectos técnicos ou estéticos do próprio objeto que pode ser percebido por todos, mesmos por aqueles que não são pares do campo. Nunca se menciona que há um grupo social envolvido, que ele foi desprestigiado ou silenciado, ou mesmo o contrário, que foi superestimado.

Designers recebem "briefings", comandos precisos sobre aquilo que devem projetar, mas não se fala sobre quem oferece estes "briefings". Nos bancos escolares aprendem a coletar por si próprios os da- dos que necessitam para a elaboração dos projetos, mas trata-se de um fictício exercício acadêmico.

Não pensam ou não mencionam que o meio social onde irão trabalhar o "briefing" pertence ao dono da indústria ou algum intermediário seu. Se quem ofereceu os dados para elaboração do artefato - o comanditário - desconsidera que durante a fase "coleta de dados", anulam ou desvalorizam o valor de uso do objeto e finalmente quem irá utilizá-lo concretamente, o projeto ficará seriamente comprometido. Daí embora tenham sido preparados para realizar todas as etapas do projeto, não desconfiam que agora os objetos de design passam a ser entidades fora do tempo e do espaço. Passam a possuir qualidades próprias que independem do meio social para o qual ele é concebido e produzido, isto é, o projeto atende apenas a demanda do comanditário ou de quem ofereceu o "briefing". Mas para on-de vai o respeito à "vontade" ou o "desejo" do usuário? Este aspecto passa a ser um detalhe que se confunde com a vontade do comanditário, afinal é ele que deve identificar qual é a verdadeira vontade do usuário.

Do mesmo modo verificamos que os pares do campo não conseguem relacionar a sua prática profissional com as outras práticas humanas. A prática do design é pensada isoladamente como algo único e muitas vezes superior a outras práticas que empregam o projeto como base de sua atividade profissional, tal como os artistas julgam que somente eles sabem o que é a arte e como são os únicos a se- 
rem capazes de realizá-la. Se não percebem que todas as práticas humanas são comuns, isto é, que todas as formas de atividades humanas se equivalem, ou seja, são formas de trabalho, podem afirmar que a prática do design é a única prática humana que serve para solucionar problemas. Quando são confrontados à constatação de que todas as práticas humanas existem para solucionar problemas humanos, não sabem o que dizer e formulam respostas incertas ou sem ca-racterísticas muito nítidas. Se a afirmação "solucionar problemas" é o único argumento capaz de definira realização de um objeto de design, isso é o mesmo que afirmar que nenhuma outra prática humana pode solucionar problemas.

Outro argumento que foi apresentado de forma recorrente nas entrevistas e que também se propõe a ser o estofo ontológico da prática do design é o termo interdisciplinar. Ora, do mesmo modo que a noção "solucionar problemas" é tida como a única a ser exercida pelos designers, os pares do campo afirmam que a interdisciplinaridade parece ser exclusiva dos designers, uma espécie de "raison d'être" da prática do design. O dislate dessa afirmação às cegas, dita a torto e a direito por todos os pares e não importando o grau de especialização, nos causou grande admiração. Uma ciência só é ciência enquanto considera o todo e não a parte. A ciência procura sua justificativa no universal, daí não há ciência do particular ou do contingente, mas do universal. $\mathrm{O}$ argumento mais cien- tífico é sempre o mais universal, o mais abrangente e válido para todos os exemplos particulares. Deste modo, desde Aristóteles a ciência, qualquer ciência, é interdisciplinar, aliás, qual seria a ciência que não é atravessada por outras formas de saber.

Para concluir resta-nos mais uma ponderação em relação às respostas obtidas: quando um professor doutor afirma que o "Design é uma disciplina e profissão que projetam interfaces físicas e digitais", mais uma vez não podemos nos furtar a lembrar dos gregos e de tudo que diziam sobre o que os designers supõem que estão inventando, o que confirma a mediocridade dos pares do campo. Afirmar que design é a profissão de quem projeta interfaces físicas e/ou digitais é o mesmo que enunciar que Homero era poeta, pois fazia poesias e Maradona foi futebolista, pois jogava futebol. Mas poderíamos, caso desejarmos, mudar o exemplo: um marceneiro é marceneiro pois fabrica objetos de madeira. Enfim, tal como em Aristóteles, tratar-se-ia de uma explicação baseada na noção da causa eficiente. $\mathrm{Na}$ qual, por conta de uma ação, se produz um efeito, ou de acordo com exemplo, onde o escultor seria causa eficiente da escultura. Daí perguntamo-nos: será que nossos pares leram ou ouviram falar de Aristóteles? Julgamos que essa pergunta já tenha sido respondida, enfim, os pares não oferecem respostas ou explicações, mas dizem qualquer coisa e dizer qualquer coisa é tautologia, não aprofundam sua compreensão. 
Assim, além da platitude dos pares em relação aos fundamentos teóricos do design e pelo visto em relação a todos os conhecimentos disponíveis desde os gregos, generosamente podemos afirmar com alguma segurança que as respostas oferecidas se prenderam aos aspectos teóricos que poderíamos designar de periféricos ou secundários. Definem os projetos de design de modo epidérmico e atendose maiormente às explicações de natureza formalista, atendo-se aos aspectos de configuração ou estéticos, que são compreendidos como questões técnicas de aplicação prática.

Verificamos que essa é uma antiga noção de design e que os pares se mobilizam para reproduzi-la e mantê-la como uma espécie de crença e nunca uma argumentação científica, com os dados que a comprovem. Em todas as entrevistas tivemos apenas uma menção destes aspectos como valores simbólicos e não houve nenhuma menção do objeto de design em relação ao contexto histórico concreto no qual os objetos industriais estão inseridos. Conforme vimos, os artefatos ou objetos industriais são apresentados fora de qualquer representação temporal ou espacial, do mesmo modo que servem para atender às demandas do "mercado" ou dos "usuários", finalidades nelas próprias e que se tornam manifestas abstratamente.

Do conjunto destes dados apresentados nas entrevistas pudemos concluir que entre os pares há pouca reflexão teórica em relação à produção dos objetos ou produtos, isto é, mercadorias concebidas e produzidas por designers. Ignora-se ou não se menciona que a prática profissional de nossa categoria profissional. Os pares operam na manutenção de uma forma ideológica capitalista e com o intuito de saciar os desejos - estes criados simbolicamente pelos próprios agentes de produção, a indústria. E mencionam também que o desenvolvimento tecnológico ocorre por si mesmo, que os cientistas descobrem coisas e que elas imprimem transformações; que essas descobertas são fruto da vontade das pessoas, das que inventam e das que compram as coisas inventadas. Não tivemos nenhuma resposta que mencionasse que as descobertas tecnológicas são uma demanda do nosso modo de produção para reprodução da exploração do trabalho e que os inventores ou pesquisadores são solicitados a ampliar seus conhecimentos para produzir tecnologias que possam aumentar a produção da mais valia Os agentes de recepção - os consumidores ou usuários - são vistos como seres passivos e que independentemente de suas origens sociais "reconhecem" intuitivamente o "bom" design, afinal a finalidade de um "bom" design é algo que se pode ver objetivamente, está na cara e é autoexplicativa.

De nossa parte defendemos que a fundamentação teórica deveria ser simétrica à prática, pois são estes os dois fatores que fazem parte do processo de significação dos objetos industriais. 


\section{Referências}

ALTHUSSER, Louis. Ideologia e aparelhos ideológicos de Estado. $3^{a}$ ed. Lisboa: Editorial Presença - Martins Fontes, 1980.

APPADURAl, Arjun. A vida Social das Coisas. Rio de Janeiro, EDUFF, 2015.

BOURDIEU, Pierre. Vocabulário. Catani, Afrânio Mendes et alii. (Orgs.) Belo Horizonte: Autêntica, 2017.

BURAWOY, Michael. O marxismo encontra Bourdieu. Campinas, São Paulo: Editora Unicamp, 2010.

CIPINIUK, Alberto. O Campo do Design e a crise do monopólio da crença. São Paulo: Blücher, 2017.

DOWBOR, Ladislau. A era do capital improdutivo. A nova arquitetura do poder, sob a dominação financeira, sequestro da democracia e destruição do planeta. São Paulo: Autonomia Literária, 2017.
FORTY, Adrian. Objetos do Desejo. Design e Sociedade desde 1750. São Paulo: Cosac \& Naify, 2007.

LESSA, Washington Dias. Objetivos desenvolvimento e síntese do projeto de design: a consciência do método. In.: WESTIN, Denise et COELHO, Luiz Antonio. Estudo e prática de metodologia em design nos cursos de pós-graduação. Rio de Janeiro: Novas Ideias, 2009.

MILLER, Daniel. Trecos, troços e coisas. Estudo antropológico sobre a cultura material. Rio de Janeiro: Zahar, 2013.

MUNARI, Bruno. Das coisas nascem as coisas. São Paulo: Martins Fontes, 2002.

SOUZA, Jessé. A classe média no espelho. Sua história, seus sonhos e ilusões, sua realidade. Rio de Janeiro: Estação Brasil, 2018. 